\title{
The management of schools' websites in Cantabria, Spain
}

\section{Carmen Álvarez Álvarez \& José Inés-García}

To cite this article: Carmen Álvarez Álvarez \& José Inés-García (2017) The management of schools' websites in Cantabria, Spain, Research in Learning Technology, 25:1, 1270579, DOI: 10.1080/21567069.2017.1270579

To link to this article: http://dx.doi.org/10.1080/21567069.2017.1270579
(C) 2017 The Author(s). Published by Informa UK Limited, trading as Taylor \& Francis Group.

Submit your article to this journal

\section{Шll Article views: 2309}

Q View related articles $₫$

View Crossmark data $\nearrow$ 


\title{
The management of schools' websites in Cantabria, Spain
}

\author{
Carmen Álvarez Álvarez (iD) and José Inés-García \\ Department of Education, University of Cantabria, Santander, Spain
}

\begin{abstract}
School websites are not only sources of information and documentation, but also means of communication that are increasingly being accessed by members of society, especially by the different educational communities, thanks to the democratisation of Internet access. This paper deals with a qualitative research project in which information and communication technology coordinators of infant and primary publicly funded private schools (concertados) and state schools in urban, rural and semi-urban/rural areas within the Region of Cantabria (Spain) were interviewed in order to understand how school websites are managed. The findings show a range of views and practices in the schools' management of their websites, some positive developments in their uses and functions, and numerous opportunities for improvement. School websites are essential communication tools, which need to be continuously improved/updated by their managers, with the support of the education authorities.
\end{abstract}

\section{ARTICLE HISTORY}

Received 23 February 2016

Revised 24 October 2016

Accepted 3 December 2016

\section{RESPONSIBLE EDITOR}

Carmen Álvarez Álvarez, University of Cantabria, Spain

\section{KEYWORDS}

School website; ICT coordinator; educational community; school improvement; Spain

\section{Introduction}

In the information and communication society that we live in, it has been internalised that the Internet provides the answer to almost all of our questions (Castells, 2006). Schools therefore face the challenge of satisfying the curiosity of online visitors through their institutional website (Du Preez, 2007; Hartshorne, Friedman, Algozzine, \& Isibor, 2006; Hartshorne, Friedman, Algozzine, \& Kaur, 2008; Honiges, 2013; Hu \& Soong, 2007; Poock, 2005; Stewart, Jacob, \& Jensen, 2012; Tamatea, Hardy, \& Ninnes, 2008; Tubin \& Klein, 2007).

International studies have shown that school websites are gaining more and more interest, although further research into the subject is required (Hartshorne et al., 2008; $\mathrm{Hu} \&$ Soong, 2007; Tubin \& Klein, 2007). School websites are being visited ever-more frequently, and in the future this trend will increase due to the greater levels of Internet connectivity of stakeholders in education processes and society as a whole (Hartshorne et al., 2006, 2008; Hu \& Soong, 2007; Tubin \& Klein, 2007).

The person responsible for the school website is the information and communication technology (ICT) coordinator (Balas, Mirea, \& Mirea, 2014; McGarr \& McDonagh, 2013; Rodríguez-Miranda, Pozuelos-Estrada, \& León-Jariego, 2014). In the coordinator's absence, that responsibility may be taken on by a member of the management team, whose main task is to ensure the use of the new technologies in the school. A study in 
Ireland conducted by McGarr and McDonagh (2013) showed that the ICT coordinator plays an important role in tasks such as the implementation of ICT in the curriculum and the maintenance of computer equipment within the school. A study carried out in Spain by Rodríguez-Miranda et al. (2014), based on 101 ICT coordinators in the Andalusia region, revealed that their main roles are working with and guiding teachers in the use of ICT, and enabling the use of digital content in the school, with the administration of the school website being their least important function. Perhaps this explains why management of the school website has been the least researched of all the tasks performed by ICT coordinators.

However, this website management is an important task, as the site is visited both by stakeholders who are internal to the school (staff, families and students) and by those who are external (potential education professionals, potential families and students, and society in general), and it serves as the school's showcase. In fact, a study by Honiges (2013) on the image of schools in their communities showed that one of the strategies that promoted a positive image of these centres was the school website. The reason was that it enabled visitors to see if the school used technology in an innovative way, if it had a two-way relationship with the community, if it had links with social networks, and if it engaged in educational marketing. Before families choose a school for their children, they are increasingly researching the different institutions, communicating with other families or teachers, and accessing the schools' official websites. They consider the websites to be the most objective comparison tool between schools (Cucchiara \& Horvat, 2014). In addition, if the sites are regularly updated, members of the school community regularly visit them, because they are useful tools for obtaining information on events, downloading forms, dealing with administrative procedures, answering questions, getting insights into teachers' work on a regular basis, finding out about specific school events, etc. (Hu \& Soong, 2007).

While school websites have to achieve an undetermined range of roles and objectives (Tubin \& Klein, 2007), they all have the challenge of providing truthful, useful, comprehensive, relevant and up-to-date information (Du Preez, 2007) for all kinds of people, including those with disabilities, in order to prevent informational exclusion (LOMCE, 2013) ${ }^{1}$. This challenge falls at the feet of the ICT coordinator. However, as revealed by a study by Rodrigo Rodrigo, Chacón Peirats, San Martín Alonso, and Gallardo Fernández (2014), there is often a lack of prior training and poor recognition of the ICT coordinator's work, and they have little support from the management team and teachers in the school. In fact, for the design, development, implementation and evaluation of the website to be of high quality, the ICT coordinator's work should be based on leadership, trust and the distribution of responsibilities (De Paula Rodríguez \& Pozuelos Estrada, 2009). Updating and constantly improving a website can be an arduous task if it falls to a single person, especially if there is no feedback to help identify ways of improving it.

Today there are three major trends in official school sites: (1) a greater focus on the content, and a desire for thoroughness; (2) a focus on marketing, with the downside that a biased image of the school is sometimes provided (Honiges, 2013; Tamatea et al., 2008); and (3) a greater focus on communicating with visitors, which is the least developed trend so far (Du Preez, 2007; Hartshorne et al., 2008; Hu \& Soong, 2007).

The ideal site should provide accurate, useful, comprehensive, relevant and up-todate information to potential visitors, both internal and external to the school (Du Preez, 
2007; Hu \& Soong, 2007); facilitate communication with them to the greatest extent through the Web; and not overindulge in marketing.

In the Cantabria region, all publicly funded schools have at least one official Web portal (generated by the Educantabria platform, which is under the aegis of the Spanish Ministry of Education, Culture and Sports), and sometimes another portal on a proprietary domain, or a blog that is managed independently. This illustrates the importance given by them to the Internet: the schools in the region are in the process of opening up to society as a whole through their web presence. However, there are notable differences between the websites of the schools in the region. This study seeks to explore how these sites are being managed by schools and public authorities today.

\section{Method}

This paper describes a study on the management of websites of primary education schools supported by public funding in the Cantabria region (known in Spanish as Comunidad Autónoma or Autonomous Community).

The objective was to obtain first-hand knowledge as to how websites were managed on a day-to-day basis by schools in the Cantabria region, in order to ascertain the importance accorded to them. It seemed appropriate to design a study to become acquainted with some of the people responsible for managing school websites on a regular basis. This was intended to meet the overall objective of the study, as well as to discover what their training was, what importance they gave to websites as a means of communication, how they assessed the website in their particular school, and the resources provided by the Comunidad Autónoma.

The lack of any prior qualitative studies of this kind served as an incentive to choose a methodology based on in-depth interviews conducted with key informants - that is, ICT school coordinators and managers of Educantabria, the educational portal whereby the regional authority provides virtual support to, and maintenance of, the official websites of schools that want to use it. Potential participants were identified, contacted and asked to take part in, and consent to, a personal interview. All of the websites in the region were analysed (which resulted in another study still pending publication) and a number of relevant schools were identified and contacted. Basically, this study consisted in identifying all of the Comunidad Autónoma websites (202 schools) in order to analyse their layout, organisation of information, content, usefulness and the role given to the educational community. The purpose was to see whether it was possible to assess the schools' teaching methods and internal dynamics.

As noted by Hernández (2014), interview-based studies can be crucial to obtain further knowledge about issues on which little previous research has been conducted, such as the present one. The results obtained from interviews (shown in the next section) can contribute to generate academic knowledge, and are in line with the basic principles of grounded theory (Charmaz, 2014).

An emergent design was employed in the study. Initially, six schools were selected as potential participants (and later contacted), with three requirements being taken into account: (1) that both public and publicly funded private (concertados) schools - primary and infant education - were represented; (2) that they served urban, rural and semiurban/rural environments, in order to better understand the role played by the 
management of school websites in all types of schools in Cantabria; and (3) that their school websites were diverse, in terms of both their quality and the extent to which they were kept up to date, so that various ICT coordinators with different degrees of involvement in the development of their school website could be contacted. The researchers believed that six interviews would be sufficient to encompass all the issues of interest and have a highly diverse range of participants. Some of the schools did not respond to our request for collaboration and therefore another school with the same characteristics was found to replace the one originally selected.

Once this data collection stage was completed, additional ICT coordinators were contacted in order to provide further triangulation and saturation of data. In-depth interviews were therefore ultimately held with nine ICT coordinators or managers and two managers of the Educantabria portal. The ICT coordinators and managers interviewed were distributed as follows: four worked in public schools (two urban, one semi-urban/rural and one rural) and five in publicly funded private schools (concertados) (two urban, two semi-urban/rural, 1 rural). The following abbreviations are used to distinguish between them: (P) public, (PFP) publicly funded private schools (concertados); (U) urban, (S) semi-urban/rural; (R) rural. Information related to the identity of the participants and their respective schools cannot be disclosed in the study for ethical reasons, as this was a commitment made to the respondents. Key codes were used to identify participants.

The themes dealt with in the interviews were:

(1) The people involved in the daily management of the school website, their training and their role.

(2) The history of the school's official website, its updating, how it currently works, and challenges for the future.

(3) The school's ICT resources and its assessment of the Educantabria portal.

(4) Sources of documentation for improving the school's website, reports received from visitors and the school's evaluation of its own website.

In-depth interviews were carried out to exhaust all the themes under discussion. Each of the interviews lasted approximately one hour, and consequently each of the relevant aspects was investigated to a considerable extent. All the interviews were recorded, and later transcribed and analysed using content analysis procedures to ensure that the participants' statements would be accurately represented and achieve a high level of rigour. All the participants were informed of the ethical considerations of the study, in particular regarding the anonymous use of their data in both the analysis and dissemination stages of the study.

The results were largely consistent from the first to the last interview. Therefore, triangulation of statements, individuals and schools was achieved. Once the first six interviews had been conducted, the results started to become repetitive. It was decided that three additional interviews would be carried out to ensure the consistency and reliability of the results and provide saturated data. After the nine interviews had been completed, it was considered that no additional ones were required. The transcripts were analysed using content analysis procedures. An original system of categories was thus created, based on the four major questions asked in the interviews. 


\section{Results}

The data collected shows that there are significant differences in the management of school websites in Cantabria. In order to account for the situation, the data was organised around the following themes: (1) managers of school websites, who deal with the different situations concerning the website management as noted by the ICT coordinators; (2) the websites at the initial stages and their current status, focusing on their development and, particularly, their current status; and (3) the improvement of school websites, with an emphasis on the main challenges faced by schools in optimising their websites.

\subsection{Managers of school websites}

The website managers are usually the ICT coordinators or managers, depending on the school's internal dynamics. However, while management of the school website often falls to them, most schools try to seek support among teachers (and sometimes students) to update, maintain and provide answers to all members of the educational community:

I keep it up to date, but all of the tutors send me things they do on a daily basis. They take photos, write news items and send them to me for uploading. Everybody helps, and now we have children from year 6 helping. They also help. I upload something every day. (ICT Coordinator, P.R.)

This does not always happen, and one individual may end up assuming the onerous duty of managing a website, which is perceived as something tedious that entails great responsibility and can cause problems, such as replacing the person who performs these tasks:

I'm trying to keep things going collaboratively and to let go of it a bit. I have six years to go until I retire. Every so often I say, 'If anyone wants to take this on, I won't object, I'll help this person as much as needed and I'll take a step back to concentrate on teaching.' But nobody wants to get into this quagmire. (ICT Coordinator, P.U.1)

There are also cases of schools where, as no teacher would take care of the ICT coordinator role, the head teacher had to take it on, despite lacking the training and the time to do it, with negative consequences for the development of the website.

There is a website that is there, but it is not up-to-date or anything. It is not managed by anyone on a daily basis. If I were the head teacher of another school and had time to develop the website, I would manage it, but I have many more things to do, so I don't. The school doesn't have an ICT coordinator because these are volunteer positions that require training, and you cannot force people to be a coordinator of anything. (ICT Coordinator, P. U.2)

Management of the website may also fall to a group of teachers or a company, especially at the beginning, due to a lack of teachers with the training to develop websites. This involves a financial expense for the school until they can manage it independently. A change towards independent management has been made possible thanks to the ease of new website structures and formats, similar to blog posts, which require less knowledge and simplify the work of keeping the website up to date. 'We set 
the website up earlier this year. Two teachers who are the most knowledgeable about ICT and are very creative were very keen and spent a long time with the ICT expert' (ICT Coordinator, P.S.).

In the case of publicly funded private schools, the website is not always the responsibility of the school, but of a religious congregation. It is updated more sporadically, which causes systematic obsolescence and a lack of response to the current needs of the educational communities, who are accustomed to accessing online information.

Our website is not ours, we do not manage it; it belongs to the congregation. Every year we send what we think should be on the website to the Web coordinator and it is uploaded. It is a joint website for all the schools in the congregation worldwide. The last thing we uploaded was from the end of last year. We sent it to the coordinator and he put it up. I am the ICT coordinator of the school, but I take care of other things (ICT Coordinator, PFP.R.).

All the participants noted that no special skills or knowledge are required for managing a website. Today, school websites are very intuitive to update, as internally they are very similar to blogs. For schools that use the Educantabria portal to host their websites, training courses are on offer to ICT coordinators, and there are tutorials available on the website.

Since 2013 there has been training for schools that wish to experiment with the new platform, and on the website itself we have a lot of videos where we have been doing the processes, and we've been recording them so people can teach themselves how to put a blog up, how to design a website, how the different areas are changed on the page, how it is divided into sections... (Educantabria Advisor 1)

However, websites are often a secondary concern for those responsible for their upkeep.

I think the ICT coordinator gives a lot of importance to the application of technology in the classroom and has very few hours available to do it. For the ICT coordinator, school website work is a minor task, compared to other duties. Because he has to ensure that students have their computers ready when they go to the classroom, they have the relevant educational applications available, advise a colleague on how to make their class webpage, etc. (Educantabria Advisor 2)

\subsection{Websites at the initial stages and their current status}

The first school website in Cantabria began in 1984 in an urban state school. However, websites only became popular later. Between 2005 and 2007, the Department of Education of Cantabria launched the first tool to enable all schools to create their own website. This has been under continuous development and culminated in the Educantabria portal, which is a much more advanced, comprehensive, complex and secure tool.

The initial stages of school websites were difficult in all cases: IT tools were not advanced and programming languages required users to be trained, processes were much slower, etc.

When we started to work on websites I had no idea. It was when hardly anyone had seen a computer, they were connected to a basic telephone line. At the time there was a lot of awareness in the school about ICT and when the first websites came out we said 'let's see 
how his goes', and we did one that was very static, with poor interaction options..., a bit like a website 1.0. (ICT Coordinator, P.U.1)

The first Web portals made schools very dependent on companies to maintain them, but this is not the case anymore.

Before this website we have now there was one made in Flash and a company was hired. It was completely static and also every time you had to make a change, it had to be made by the company, we had to talk to the company, and pay, it wasn't practical... This was the type of websites people used in the past, but now we want them to be more practical. (ICT Coordinator, PFP.S.2)

Currently, all the schools in Cantabria have their own school website in the Educantabria portal and only need to keep it updated; alternatively, they may choose to create one on a private domain or use a blog. Maintaining this type of website format is fairly intuitive, so there is no need to be a computer expert or rely on a company.

Having a full school website today is very simple. You enter by clicking on 'access' with your username and password and edit what you want. It is very easy. It's like a blog. It is very simple. It isn't complicated at all. (ICT Coordinator, PFP.U.1).

However, there are many challenges for the improvement of school websites, as will be discussed in the next section.

Currently, websites primarily serve two types of purposes: information and marketing. All respondents stated that the main role of official websites is to inform.

Our website is mainly intended for information purposes, although we do a lot that we do not show on it. The website could be much more dynamic, it could have more news about everything we do. Sometimes the Department of Education releases projects we are already working on and then we realise that we don't really display everything we do, and we should do it. (ICT Coordinator, PFP.U.1)

Nevertheless, the ICT coordinators of the two publicly funded private schools (concertados) who were interviewed made it clear that the website is an excellent showcase, and looking after it ensures that new families will be keen to enrol their children in the school.

It is intended to make the school known, to ensure that parents send their children here and not to another school, to promote enrolment. We also want to introduce people to the vocational training courses, because almost everyone here knows that this is a school, but few people know that there is vocational training. We always try to release information about the vocational courses to inform people about them. (ICT Coordinator, CS2)

Those schools that update their websites frequently are enthusiastic about their websites' potential, and are motivated to continue to improve them.

During the enrolment period, school websites become particularly important, because they are used to obtain information, which can be decisive in terms of decisionmaking together with discussions with other families that have students enrolled in the school.

One way to know is word-of-mouth and another one is reviewing websites. Then of course, they look at the website and say 'your website is nothing like the others I've seen around, 
this one provided proper information'. And indeed, there are new students who surprise you with the knowledge they already have of the school. (ICT Coordinator, P.U.1)

Students also use websites when they provide information that interests them; for example, curriculum content, learning proposals and/or complementary activities or photographs and contributions from other students. 'The students mainly visit the classroom blogs that are linked to [the website]. They very often look at this. For example, [they use] the English blogs ... in class and at home' (ICT Coordinator, PFP. U.1). The same applies to the Authority. 'The inspector has also been reviewing it regularly because she always tells us, "you have put this up, that's great, you have put the other thing up, you can put this up..."' (ICT Coordinator, P.R.). 'Many families have no idea what is being done, and now as they access the website and see it, they like it. Many people are visiting it, and that's something we did not expect' (ICT Coordinator, PFP.U.2).

\subsection{Improvement of school websites}

Most schools face many challenges in managing their websites. One of these challenges pertains to providing information about the school's activities in broad terms, to meet any user's demands for information. 'I think we could promote some aspects, some new plans or projects that we launched this year. We are developing Department of Education plans and projects and it is good that people are a little more aware of this' (ICT Coordinator, C.U.2).

Similarly, the websites must provide services to users that are as broad as possible, and that go beyond simply informing: the challenge is to enable two-way communication.

We have created an app that gives information about our educational project, location, etc. It enables telephone calls to the school to be made from the app, [and allows people] to see a map to get to the school, to report incidents or absences, etc. We also have many online forms that are very useful. For example, we have a Robinson list for families who want to sign up to receive information by e-mail only, not on paper. So we save paper and gain immediacy, and $65 \%$ of families are already benefiting from the service. (ICT Coordinator, P.U.1)

A continuing challenge for any school is to update their website frequently.

One of the things that I was very clear about when I became a head teacher was that I wanted to renew the website, I wanted it to be up-to-date and dynamic. The fact that you access a website and see last summer's trips makes you feel that it is not cared for, it is not monitored and it is useless; that you have it up just because you have to... Since we have had a couple of people involved in ICT and the website, it is constantly updated. (ICT Coordinator, PFP.U.2)

Although most schools are far from achieving continuous updating, the most forwardlooking ones are clearly aware that progress has to be made, as they see new advantages, such as the usefulness of conveying the activities undertaken each term and making education more visible.

The news section is updated constantly. Not the contents menu, as we're involved in a restructuring process. That is where we take the information for the annual magazine. What 
is not published doesn't exist, and we want everything we do to be visible to the educational community and all those who have come in contact with our website. (ICT Coordinator, C.S.1)

Another challenge related to websites relates to the need to strongly promote interaction mechanisms with users, to enable the website to be a cutting-edge communicative tool that goes beyond being a mere one-way channel of information from schools to society. However, both the schools and the Education Authority have doubts about the best way to move forward in this regard without causing problems.

We could have forums on the websites, but in a forum anyone can write the most outrageous things, and unless you have someone constantly moderating the forum, it reaches everyone and that's a problem. The interactive part is good because everyone can see, but not controlling it is a risk. That is why I put an email contact on the website, and not a forum. (Educantabria Advisor 1)

An increasing number of educational institutions prefer to use social networks such as Facebook, Twitter and Instagram, which are perceived to open up many opportunities for schools.

I think that Facebook is very effective. Many people do not visit the school website, but follow us on Facebook, and having an Instagram account means that we are able to show the photography contests or the library initiatives. Now the next step is to for parents and students who follow us on Facebook to make comments and contributions. (ICT Coordinator, P.S.)

However, an aspect of great significance in the improvement of school websites, partly as a result of the lack of research on the subject in Spain, is the lack of reference points for schools to look to in terms of website design. During the design process, ICT coordinators tend to look at other sites, generally randomly, for inspiration. But once the basic structure has been designed, all the ICT coordinators said that it is then left to intuition and improvisation. The lack of scientifically substantiated references from national or international publications on how to further the improvement of websites reduces their enhancement opportunities.

When we designed the website, we looked at a lot of pages to see what buttons we wanted, and we chose from among several options, but now improving the website is something of an intuitive process. We upload what we think best. We are not inspired by anything. It is all intuition, we upload what we consider appropriate using our own judgement. (ICT Coordinator, PFP.S. 2)

In this sense, only self-criticism and reflection on the progress made, as well as requests for information made by external agents to the schools, serve to provide some guidelines, which are inevitably blurred, for action in the improvement of this tool.

\section{Conclusions}

The results lead to the following conclusions about managers of school websites, the general development of websites and the challenges of school websites.

First, it was found that the managers of school websites vary greatly in their levels of involvement, which has an impact on their quality. Overall, participants expressed a 
slightly higher interest in the use of websites in publicly funded private urban schools, as websites are deemed to be used for informative and marketing purposes, and play a part in attracting new students (Honiges, 2013). All of the collected statements showed that managing a school website today is easy and does not require specific sophisticated training, although it does take time and dedication. A barrier in the development of this tool could be the very identity of ICT coordinators, who see themselves more as support for their colleagues in the implementation of the ICT curriculum than as the institution's website managers, with the latter task taking second place (Rodríguez-Miranda et al., 2014).

Additionally, very different management practices were found depending on the people who were responsible for the website; that is, whether there was a single leader, several leaders, collaboration with a company, dependence on a larger home website such as that of a religious congregation, etc. All of this suggests that for a website to remain up to date and thorough, and provide useful information, the collaboration and cooperation of everyone in the school's educational community is needed; that is, the management team, teaching staff, parents' association, partner organisations, etc. It is very difficult to maintain an up-to-date and comprehensive website if a single individual is responsible for it (ICT coordinator or manager). In this sense, it is necessary to give more recognition to the work of ICT coordinators and encourage schools not to entrust management of the website to a single individual (Rodrigo Rodrigo et al., 2014). It would also be useful for schools to increase the hours spent on developing their website and coordinating the ICT curriculum.

It must be noted that the general development of websites has been mainly positive. The initial stages were hard: there was large dependence on computer experts and the resulting websites were static. However, today's websites are much easier to create and maintain and the educational authority - with its Educantabria format - provides technological and training support. This does not mean that managers of the websites do not need to continue working to ensure that the websites are thorough and fully up to date, but that the current situation, compared with the past, is highly positive ( $\mathrm{Du}$ Preez, 2007). The various public administrations, therefore, need to continue to generate systems for the training and support of schools.

Schools are benefiting from the information and marketing opportunities offered by websites, but they should also begin to explore becoming more interactive, for which forums or social networks could be of help. At present there are few schools that use these networks; however, it is becoming increasingly common for citizens to have social networking profiles and to look at them daily. The use of these tools could contribute greatly to the improvement of communication in schools, not only with the educational community, but also with others who are connected to the Internet. Some pioneering schools have already created profiles on Facebook, Twitter and Instagram, which they use to post up-to-date information about school life, and their number of followers increases on a daily basis. Additionally, as website managers themselves have said, when they create these profiles, or update their websites, they gather new followers, which motivates ICT coordinators to further improve their Web tools and implement new ideas and content, creating a positive feedback loop that benefits all users.

It can be concluded that the management of school websites is fraught with challenges and opportunities for improvement, namely giving full information about the 
school's activities in order to fulfil the information needs of all users; providing services to users beyond the merely informative purposes; providing regular updates; generating new avenues of communication with the community of visitors, etc. From all these challenges, one seems particularly problematic and relevant: conducting further research on school websites in Spain. The lack of national reference points, and the difficulty in accessing international models, which are often in English, leave little room for schools and ICT coordinators to professionally improve this tool, which means they miss out on opportunities for enhancement, leaving them over-reliant on intuition and improvisation. The current information society demands that schools deliver quality not only academically, but also on their Web portals.

In the future, it would be of interest to carry out research specifically on the best websites in our region, by selecting 10-20 of them and conducting interviews with ICT coordinators to identify how they managed to create high-quality websites.

\section{Note}

1. Spanish General Act of Parliament on the improvement of quality in education.

\section{Disclosure statement}

No potential conflict of interest was reported by the authors.

\section{ORCID}

Carmen Álvarez Álvarez (D) http://orcid.org/0000-0002-8160-2286

\section{References}

Balas, E., Mirea, D., \& Mirea, L. (2014). The ICT coordinator in school a XXI century education. Journal Plus Education, 10(1), 312-317.

Castells, M. (2006). La sociedad red [The network society]. Madrid: Alianza.

Charmaz, K. (2014). Constructing grounded theory. London: Sage.

Cucchiara, M., \& Horvat, E.M. (2014). Choosing selves: The salience of parental identity in the school choice process. Journal of Education Policy, 29(4), 486-509. doi:10.1080/ 02680939.2013 .849760

De Paula Rodríguez, F., \& Pozuelos Estrada, F.J. (2009). Contributions on the development of teachers' training in ict schools. case study. Pixel-Bit: Media And Education Journal, 35, 33-43.

Du Preez, H. (2007). Issues to consider during the development and promotion of a primary school web site. Pretoria, South Africa: University of Pretoria.

Hartshorne, R., Friedman, A., Algozzine, B., \& Isibor, T. (2006). Secondary schools online: Are high school web sites effective? American Secondary Education, 34(2), 50-66.

Hartshorne, R., Friedman, A., Algozzine, B., \& Kaur, D. (2008). Analysis of elementary school web sites. Educational Technology \& Society, 11(1), 291-303.

Hernández, R.M. (2014). Qualitative research through interviews. its analysis by grounded theory. Pedagogical Issues:Journal Of Educational Sciences, 23, 187-210.

Honiges, A. (2013). School image in the context of new communication technology. Knowledge Horizons-Economics, 5(2), 162-166.

$\mathrm{Hu}, \mathrm{C} .$, \& Soong, A.K. (2007). Beyond electronic brochures: An analysis of Singapore primary school web sites. Educational Media International, 44(1), 33-42. doi:10.1080/09523980600922761 
LOMCE. (2013). Organic Act $8 / 2013$, of December $19^{\text {th }}$, for quality improvement of education, BOE of December $10^{\text {th }}, 2013$.

McGarr, O., \& McDonagh, A. (2013). Examining the role of the ICT coordinator in Irish post-primary schools. Technology, Pedagogy and Education, 22(2), 267-282. doi:10.1080/ 1475939X.2012.755132

Poock, M. (2005). Determining the design of effective graduate school web sites. College and University Journal, 80(3), 23-26.

Rodrigo Rodrigo, M., Chacón Peirats, J., San, Martín, \&, Á., \& Gallardo Fernández, I. (2014). Perceptions around the ICT Coordinator in smart schools. A case study. To educate, 50(1),167184.

Rodríguez-Miranda, F., Pozuelos-Estrada, F.J., \& León-Jariego, J. (2014). The role of ICT coordinator. Priority and time dedicated to professional functions. Computers \& Education, 72, 262-270. doi:10.1016/j.compedu.2013.11.009

Stewart, T., Jacob, A., \& Jensen, L. (2012). School site visits: What can we learn from choice schools in Milwaukee. Milwaukee Evaluation Report, 34.

Tamatea, L., Hardy, J., \& Ninnes, P. (2008). Paradoxical inscriptions of global subjects: Critical discourse analysis of international schools' websites in the Asia-Pacific Region. Critical Studies in Education, 49(2), 157-170. doi:10.1080/17508480802040241

Tubin, D., \& Klein, S. (2007). Designing a school website: Contents, structure, and responsiveness. Planning and Changing, 38(3-4), 191-207. 